CTC (1991) Research by trainees. A report by the Working Party of the Colleglate Trainees' Committee. Psychiatric Bulletin, 16, 239-243.

GAYARD. D.G. \& LAMBERTY, J.M. (1989) The attitudes of junior anaesthetists to research. A survey. Anaesthesia, 44, 681-683.

LEWrs, S. (1991) The right stuff? A prospective controlled trial of trainees' research. Psychiatric Bulletin, 16, 478 480.

BRIAN A. KIDD, Tone Vale Hospital, Taunton TA4 1DB; CAMERON STARK, Department of Public Health, Paisley, Scotland, PAI 1DU; and TOM HENDERSON, Parkhead Hospital, Glasgow, Scotland

\section{Issues in the changing services for the psychiatry of learning disabilities}

Sir: In the Yorkshire region consultant psychiatrists in learning disabilities (LD) meet regularly. Our discussions show changes in services for learning disabilities from hospital to community are raising many questions.

Service arrangements. The former Yorkshire 'subregional admission bureaus', with two consultants in each of five extensive areas, have been replaced by districts making their own provision. Now services are fragmented and varied. A few districts still have no consultant. More districts have joint posts in mental illness and LD. These function well, but the consultant/ population ratio is below the $1: 200,000$ recommended by the Royal College.

Consultant sessions. A consultant may operate a 'consultational model' of practice, seeing patients, then returning them to the family doctor and community learning disabilities teams (CLDTs). If a consultant adopts a 'liaison attachment model' and becomes a member of the community team offering continuing care, more sessions are needed.

Case load. A newly appointed consultant may attract many new patients with the implication there is an 'iceberg' of unmet needs. To provide a comprehensive service the consultant needs NHS beds for admissions.

Children. After hospitals ceased admitting longstay children many consultants treated no children. Now children with LD and "challenging behaviour' come to CLDTs. They may be helped by the consultant in LD in collaboration with paediatricians and child psychiatrists.

Follow-up of discharges. Some residents in community units have long histories of mental disturbance. These may involve frequent and time-consuming visits from the consultant. Junior staff, medical GP clinical assistants can contribute to this care.
Medical audit. A small number of regional consultants offers scope for regional and subregional audit of referrals, waiting lists and times, case loads, records, diagnoses, mortality, challenging behaviours, epilepsy, psychiatric medication. treatment and follow-up in the community.

The meetings of the Yorkshire consultants in LD provide a forum for discussion of questions members would otherwise face in isolation. No doubt these topics arise across the country. The recognition of issues is a first step to their solution.

Douglas A. Spencer, Meanwood Park Hospital, Leeds LS6 4QB

\section{Psychiatrists' hobbies}

Sir: I have audited the hobbies of psychiatrists, using Psychiatric Bulletin obituaries for the years 1991 and 1992 as the data source.

Of the obituaries of 46 psychiatrists listed, $26 \%$ were described as "devoted family person". and 19\% with no mention of interests outside psychiatric practice. Many had multiple hobbies: $19 \%$ had two, $8 \%$ three, $8 \%$ four, and $2 \%$ more.

The hobbies were literary, including reading, history, languages, poetry, writing $(24 \%)$; music (17\%); theatre and art (11\%); sports, including mountaineering, rugby, flying, golf, cricket, walking, skiing (10\%); community affairs, travel $(8 \%)$; gardening $(6 \%)$; religious interests $(6 \%)$; fishing (4\%); wine and cooking $(4 \%)$; painting $(2 \%)$; bridge $(2 \%)$; antiques $(2 \%)$. Others were house repairing (one case), engineering (one), horology (one), vintage cars (two), ecology (two), philosophy (one), archaeology (two), and politics (one).

In auditing doctors' hobbles, (Davis, 1993) found that $18 \%$ were literary, $15 \%$ music, none for theatre and art, one case of philosophy, and none for politics in a sample of 404 .

What makes psychiatrists keener on literature and arts? Is it their love of humanitarian studies which brought them to psychiatry or is it psychiatry which made them more interested in humanities? Can we see any hint in the early formative years at medical college which would foretell future specialisation? Can these interests form grounds for encouraging early conscious awareness of job cholce?

By virtue of their work, psychiatrists are interested in humanity and humanities, but can specialisation be linked with personality profiles?

DAvs, A. (1993) Doctors' hobbies. British Medical Journal, 307, 244.

G.K. GAD, Ormskirk \& District General Hospital, Ormskirk L39 2AZ 